\title{
PERSPECTIVAS DE ALGUMAS CIDADES MÉDIAS BRASILEIRAS: REESTRUTURAÇÃO E CONSUMO
}

Filipe Gomes Paulo

Graduado em Geografia - Universidade do Estado do Rio de Janeiro filipegeouerj@gmail.com

\section{Resumo}

Buscamos traçar elementos comuns a partir de processos ocorridos em diferentes escalas, considerando as diferentes realidades regionais e urbanas através da reestruturação urbana associadas ao crescimento do consumo nas cidades médias brasileiras, que tiveram rebatimentos diferentes em cada cidade e região, indicamos outras questões que permeiam a discussão sobre o consumo, dentre as quais mencionamos a difusão do crédito, o papel da propaganda e as novas sociabilidades decorrentes dos novos padrões de consumo.

Palavras-Chave: Cidades médias, consumo, escalas.

\section{PROSPECTS SOME CITIES MEDIUM BRAZILIAN: RESTRUCTURING AND CONSUMPTION}

\begin{abstract}
We seek to bring common elements from processes taking place at different scales, considering the different regional and urban realities through urban restructuring associated with the consumption growth in average Brazilian cities, which had different repercussions in every city and region, indicate other issues permeate the discussion on consumption, among which we mention the spread of credit, the role of advertising and new sociability arising from new consumption patterns.
\end{abstract}

Keywords: Medium cities, consumption scales

\section{Introdução}

Nas últimas décadas a rede urbana brasileira tem passado por significativas transformações, na qual relações hierárquicas antes instituídas apenas pelo comando de cidades maiores sobre menores tornaram-se mais fluidas e, no mínimo, são postas em questão. As novas divisões regionais e internacionais do trabalho tiveram consequências distintas em cada lugar, exigindo 
Filipe Gomes Paulo

respostas diferenciadas, inclusive do ponto de vista das rearticulações que se processaram na escala interurbana.

Isto implica em alterações das funções, estruturas e formas das cidades, sobretudo naquelas que exercem importantes papéis de intermediação na rede urbana regional, nacional ou internacional. Elas têm seus papéis e conteúdos redefinidos sob a influência de processos dinâmicos que só podem ser compreendidos a partir da reestruturação urbana e da reestruturação das cidades, considerando a diferenciação espacial e a articulação entre diversas escalas.

$\mathrm{Na}$ tentativa de compreender este processo de reestruturação urbana e das cidades, propomos um estudo comparativo de algumas cidades médias brasileiras, estabelecendo generalizações e aproximações entre elas. Nosso principal objetivo é avaliar o caráter e a dimensão das mudanças, principalmente no que diz respeito à produção social das cidades médias e seus principais agentes. Contudo, reconhecemos que o Brasil é um país continental, com diferentes formações socioespaciais e marcado por disparidades regionais, o que exige maior esforço investigativo no qual se considerem as sobreposições, as relações não hierárquicas e as articulações multiescalares, caracterizando, portanto, um grande desafio.

\section{Reestruturação urbana e regional: um olhar sobre as cidades médias}

A década de 1970 foi marcada pelo ápice de uma profunda crise no modo capitalista de produção, cuja superação se deu com a adoção de um sistema de acumulação flexível. Segundo Harvey (2007: 140), este sistema está apoiado “[...] na flexibilidade dos processos de trabalho, dos mercados de trabalho, dos produtos e padrões de consumo", o que desencadeou um processo de reestruturação econômica, política, social, espacial e ideológica em nível mundial, cuja análise nos ajuda na compreensão da sociedade e do momento econômico que ela atravessa, balizado pela difusão do meio técnico-científico-informacional (Santos, 1996). Este momento caracteriza-se pela incorporação de ciência, tecnologia e informação à produção e pela presença de novos processos em múltiplas dimensões e escalas que, combinados, redefinem o espaço geográfico. De acordo com Elias (2003), estes processos seriam a multinacionalização das firmas e a internacionalização da produção e do produto, os novos papéis do Estado, a grande revolução da transmissão da informação, a generalização do crédito e a circulação como fator essencial da acumulação. 
Filipe Gomes Paulo

Desta maneira, a reestruturação produtiva nos anos de 1970 suscitou uma requalificação dos espaços e das relações sociais, as quais atendem aos interesses hegemônicos da economia, da cultura e da política. No Brasil, a adoção do regime de acumulação flexível levou à incorporação de novas relações de produção e de trabalho, de novas estratégias de gestão e de escolhas locacionais, favorecendo, em muitos casos, a desconcentração das atividades industriais e a difusão territorial de grandes filiais de empresas nacionais e estrangeiras. Em contrapartida, estimulou a concentração e centralização econômicas, inserindo o país em uma economia globalizada, resultado de uma nova divisão internacional do trabalho.

Ao longo da reestruturação alguns processos tornaram-se significativos, como por exemplo, o acirramento da divisão social e territorial do trabalho; um maior número de investimentos em infraestruturas, integrando as regiões e dotando o território de fluidez a partir da implantação dos sistemas técnicos; a dispersão espacial da produção, na qual o capitalismo estende seus sistemas produtivos para áreas agrícolas, expandindo a produção industrial, a agricultura científica e o agronegócio em novas regiões do país; e a ampliação do consumo, produtivo e consuntivo. Correlacionados, contribuíram para a ampliação da escala da urbanização, aumentando a importância dos centros urbanos brasileiros, fortalecendo-os demográfica e economicamente, ao passo que a divisão do trabalho entre as cidades tornou-se mais complexa (Santos, 2005).

Logo, intensificaram-se as relações multiescalares - hierárquicas ou não, competitivas e/ou complementares - entre cidades dentro de uma mesma rede urbana e entre cidades componentes de redes urbanas distintas, redefinindo não somente as escalas de interações espaciais, mas também os vetores e as direções de estabelecimento dos fluxos, pondo em questão a organização piramidal das redes urbanas (Sposito, 2006). Destacam-se então as cidades com importantes papéis de intermediação nas redes, as cidades médias.

Com a nova divisão internacional e interregional do trabalho, elas tiveram seus papéis urbanos e regionais alterados, na medida em que as relações, sobreposições e articulações entre escalas foram intensificadas. Importante destacar que "las escalas deben ser consideradas en su dinámica en movimiento y sometidas a procesos de cambio y relaciones y vínculos de interpenetración escalar. Una escala sólo puede ser definida, determinada y calificada con relación a las demás” (Brandão, 2010: 247), ou seja, não é possível pensar numa reestruturação das cidades desarticulada de um processo de reestruturação urbana (Sposito, 2007). Reforçando a interdependência entre estes dois processos, Sposito (2010: 6) afirma que "[...] não teria sentido pensar as cidades médias em si, tampouco estabelecer quaisquer definições baseadas 
Filipe Gomes Paulo

em parâmetros estáveis, mas sim considerá-las como um meio para pensar a urbanização de modo mais amplo possível”. Ela chama atenção para a análise das temporalidades desses dois movimentos de estruturação, que embora estejam articulados, não são necessariamente coincidentes.

Outro aspecto que deve ser observado nos estudos sobre cidades médias é a intrínseca relação entre o espaço intraurbano e o espaço interurbano de cada cidade (Sposito, 2001, 2007). Neste sentido, em sua análise sobre a produção social do espaço e a dimensão urbano-regional do desenvolvimento capitalista, Brandão (2010) apresenta a ideia de interurbanidade. A partir da compreensão de uma sociabilidade urbana em diversos planos e dimensões espaciais, que inclui a cidade, sua hinterlândia e a própria rede urbana, o autor pensa a questão urbano-regional como importante instrumento analítico de uma economia política que manifesta os processos sociais no espaço urbano, incorporando à problematização as estruturas e os múltiplos interesses dos sujeitos produtores dos espaços intraurbanos e interurbanos. Logo, podemos compreender as novas funções e conteúdos das cidades médias através das complexas relações que elas estabelecem com cidades de maior ou menor porte, entre si e com os espaços rurais, associado ao seu processo de estruturação intraurbana e aos diferentes interesses de classes envolvidos na produção do espaço.

No que concerne às relações interurbanas, Brandão (2010) acredita que estas impulsionaram o crescimento urbano, sendo fundamentais para o avanço material capitalista. Tal avanço impôs determinadas lógicas, que “[...] transforman la naturaleza de los vínculos y densifican, diversifican y complementan circuitos, primero mercantiles y después productivos, integrando lós sectorialismos, interregionalidades y dinámicas urbanas según una división social del trabajo creciente y en otro ritmo" (Brandão, 2010: 263). Isto é, interferem com maior ou menor intensidade na estruturação das cidades. Todavia, o autor adverte para o caráter desigual e combinado do desenvolvimento capitalista, cujo processo de hegemonia atinge diferentes proporções conforme o jogo de forças políticas entre as diversas frações de classes em um dado território.

Alguns paralelos podem ser estabelecidos entre a discussão proposta por Brandão (2010) e os estudos realizados por Sposito $(2001,2007,2009$, 2010) sobre cidades médias, sobretudo com relação à importância e ao cuidado na análise das escalas espaciais e suas múltiplas articulações. Para Brandão (2010: 247), "la escala permite un plan analítico de observación privilegiado, pasible de revelar las articulaciones y mediaciones entre los cortes local, regional, 
Filipe Gomes Paulo

nacional, etc.", e é justamente este prisma escalar que permite apreender os processos gerais, as particularidades e as singularidades de cada cidade.

No debate, pensamos as singularidades como características que não existem em outras formações socioespaciais, são únicas. Porém, dialeticamente, definir o que há de singular em cada cidade requer uma observação daquilo que se constitui como geral, ou seja, dos fenômenos e processos que se repetem. Assim sendo, o singular e o geral são interdependentes, manifestando-se por meio de formações particulares, com características próprias a determinada cidade. Portanto, as particularidades representam a unidade do que é singular e do que é geral, não evidenciando apenas o que é único, mas estabelecendo características que identificam e distinguem as cidades.

Ainda que as novas divisões do trabalho, regionais ou internacionais, tenham desencadeado consequências peculiares em cada lugar, particularmente nas cidades médias, Sposito et al. (2007) reconhecem alguns processos, agentes e dinâmicas comuns que redefinem os papéis das cidades médias. Dentre os principais processos estão:

- a concentração e centralização econômicas que, associadas ao avanço do capitalismo e aos novos meios técnicos e informacionais, propiciam a (des)concentração espacial e/ou centralização espacial dos capitais;

- a melhoria e a diversificação dos sistemas de transportes telecomunicações, diminuindo os custos de circulação e permitindo uma maior mobilidade territorial para o consumo de bens e serviços cada vez mais variados;

- as formas contemporâneas de organização espacial das atividades econômicas ligadas ao comércio de bens e serviços, relacionadas ao processo de concentração econômica e desconcentração espacial;

- o consumo de bens e serviços especializados ligados à modernização do setor agropecuário, responsável por expressivo aumento nos fluxos e no consumo produtivo e consuntivo nas cidades médias.

Como principais dinâmicas estruturantes das transformações em curso, Sposito et al. (2007) apontam a difusão da agricultura científica e do agronegócio, a desconcentração da produção industrial, a disseminação do comércio e dos serviços especializados e o aprofundamento das desigualdades socioespaciais. Direta ou indiretamente, estas dinâmicas estão relacionadas à disseminação do consumo estabelecido a partir do modelo flexível, baseado em novos padrões na produção, nas relações de trabalho e nos produtos. Destarte, partimos do pressuposto de que 
Filipe Gomes Paulo

a discussão acerca do consumo e dos novos meios e estratégias de sua realização, integrada ao debate da articulação entre escalas, contribui para a compreensão da redefinição dos conteúdos das cidades médias e de sua estruturação urbana, sem desconsiderar que as transformações ocorrem no território de maneiras, intensidades e ritmos diferentes.

\section{O consumo: interseção entre escalas}

Estudar o processo de reestruturação das cidades médias requer a apreensão do movimento temporal e interescalar de análise, que compreenda também o processo histórico de reestruturação produtiva em nível mundial. Harvey (2007) traz importantes contribuições neste sentido, apontando fatores que desencadearam este processo nas diversas escalas espaciais, da internacional à local, a saber: a penetração do capital em novas esferas de atividade, a criação de desejos e necessidades e a expansão geográfica para outras regiões.

Estes fatores nos ajudam a entender a reestruturação sob múltiplos pontos de vista. Enquanto a penetração do capital em novas esferas de atividade estimulou a modernização tecnológica e a integração setorial, a expansão geográfica do capitalismo para outras regiões agregou cada vez mais lugares à divisão internacional do trabalho, contribuindo direta e indiretamente para o processo de urbanização. Esta expansão, associada à criação de novos desejos e novas necessidades, teve relação estreita com a ampliação do consumo e as mudanças nos hábitos dos consumidores.

Por reunirem as melhores condições para o desenvolvimento capitalista, qualitativa e quantitativamente, as cidades se constituíram como centros principais da produção, da distribuição, da circulação e do consumo, assumindo importante papel de comando na divisão territorial do trabalho e atendendo à demanda de expansão da capacidade produtiva e de renovação das condições de acumulação durante o processo de reestruturação. Por isso, elas contribuíram para a maior mobilidade do capital e para a dinamização dos setores econômicos e seus ramos de atividades, tornando-se importantes vetores de difusão generalizada da informação e da ampliação do consumo de bens e serviços.

O consumo como responsável por parte das alterações nos papéis desempenhados pelas cidades, por exemplo, as redefinições nas centralidades intra e interurbanas, a atuação de agentes econômicos externos, a instalação de grandes equipamentos comerciais e de serviços modernos etc., incitou também profundas transformações nas relações sociais devido ao seu poder ideológico contagiante, "que passa a representar um papel motor e perverso na sociedade 
Filipe Gomes Paulo

atual, transitando pelo próprio aprendizado e condicionamento social do consumo" (Elias, 2003: 189).

determinado pelo complexo processo constitutivo dos desejos humanos e pela lógica do lucro (Padilha, 2006). Portanto, associada à produção, a discussão do consumo é fundamental para a compreensão do movimento atual da sociedade, revelando os novos padrões do processo produtivo, e bastante pertinente aos estudos sobre reestruturação urbana e reestruturação das cidades, constituindo-se como um ponto de interseção entre diversas escalas geográficas de análise.

Alguns aspectos estão diretamente relacionados à difusão do consumo, manifestandose mais fortemente no último quartel do século XX e na primeira década do século XXI, como por exemplo: a terceirização da economia e a internacionalização dos serviços; maior utilização da pesquisa e desenvolvimento, da propaganda e do marketing; a financeirização das relações e a generalização do crédito; a disseminação territorial de equipamentos modernos de consumo, entre outros. Cada um deles influi com maior ou menor intensidade, consoante as interações entre diferentes atores de cada cidade, produzindo então particularidades, generalidades e singularidades.

No Brasil, a introdução de novas formas de produção e de consumo foi motivada pela “[...] ideologia do crescimento, no nível da nação e do estado, e a ideologia do consumo, no nível dos indivíduos" (Santos, 2007: 21). A ideologia do crescimento foi suscitada pela modernização e maior "integração" do território, que promoveu a dispersão espacial da produção e a difusão de comércios e serviços no país, passos fundamentais para a ampliação da escala da urbanização. Simultaneamente, Santos (2005: 55) afirma que houve uma [...] superposição dos efeitos do consumo consuntivo e do consumo produtivo, contribuindo para ampliar a escala da urbanização e para aumentar a importância dos centros urbanos, fortalecendo-os, tanto do ponto de vista demográfico quanto do ponto de vista econômico, enquanto a divisão do trabalho entre cidades se torna mais complexa.

A maior fluidez no território nacional associada à nova divisão interregional do trabalho e à expansão e diversificação do consumo, foram decisivos na configuração de um novo panorama urbano brasileiro, no qual, de acordo com Sposito (2007: 239-240), as cidades médias têm suas funções e conteúdos alterados em virtude de "situações geográficas mais ou menos favoráveis e atraentes aos investimentos externos e de iniciativas de atores locais e regionais, maior ou menor capacidade de se integrarem de forma mais ampla às novas formas de configuração de relações em múltiplas escalas". 
Filipe Gomes Paulo

Inegavelmente, as redefinições das divisões do trabalho, regionais ou internacionais, tiveram consequências distintas em cada lugar, em particular nas cidades médias, porém conforme mencionamos anteriormente, de acordo com Sposito (2001) determinados processos colaboraram para a disseminação do consumo na maioria das cidades:

- “A tendência recente de concentração econômica das empresas industriais, associada aos meios técnico-informacionais atuais, que possibilitam comunicação imediata, viabiliza a dissociação territorial entre o lugar das decisões e o da produção industrial" (p.630);

- “O declínio progressivo dos custos e a melhoria e diversificação dos sistemas de transportes e de telecomunicações [...] e a decorrente diminuição da participação relativa desse custo no preço das mercadorias" (p.631);

- “As formas contemporâneas de organização espacial das atividades econômicas ligadas ao comércio de bens e serviços” (p.632);

- "É no campo do consumo de bens e serviços especializados ligados à modernização do setor agropecuário, que se tem visto um avanço significativo do papel comercial e de serviços das cidades de porte médio" (p.634).

A partir destes quatro processos apontados por Sposito (2001) como colaboradores da difusão do consumo, podemos identificar duas formas da sua realização, nomeados por Santos (1996) de consumo produtivo e consumo consuntivo que, dependendo da cidade, podem ou não estar interligados. Enquanto o primeiro "[...] cria uma demanda heterogênea segundo os subespaços”, o segundo “[...] cria uma demanda heterogênea segundo os estratos de renda, mas comparável segundo as mesmas possibilidades de demanda" (Santos, 1996: 147). A aceleração do consumo, possível após uma profunda mudança ideológica durante o processo de reestruturação produtiva, induz ao aumento do número de estabelecimentos e de trabalhadores nas atividades comerciais e de serviços no país. Ademais, justifica as complexas relações que dão conteúdo à dinâmica das cidades, contribuindo para explicar sua organização interna e os inúmeros movimentos que se desenvolvem no seu interior (Ortigoza, 2008). 
Filipe Gomes Paulo

No âmbito destas transformações, é importante lembrar a complexidade e as diferenças regionais do Brasil. Para isso, devemos considerar as temporalidades e as espacialidades do fenômeno urbano, assim como suas particularidades e aspectos em comum. Sposito (2010: 6) ressalta que é [...] importante buscar, em cada contexto socioespacial e em cada período, em que um dado conjunto de variáveis denota uma dada unidade, reconhecer as particularidades dessas cidades. Além disso, é relevante apreender as circunstâncias, segundo as quais se alteram seus papéis na divisão social e econômica do espaço estabelecida em múltiplas escalas, da local à internacional. Entendemos que a apreensão dos processos e agentes envolvidos na reestruturação das cidades médias brasileiras pressupõe uma abordagem multiescalar que considere a articulação entre verticalidades e horizontalidades, continuidades e rupturas. Isto requer um maior cuidado metodológico do pesquisador, sobretudo ao avaliar a intensidade, a velocidade e o caráter das transformações. Neste sentido, os estudos comparativos contribuem para a compreensão da realidade multidimensional, permitindo o estabelecimento de generalizações, de particularidades e de singularidades através da identificação de semelhanças e diferenças entre as cidades. Não obstante sua complexidade e suas limitações, tomaremos esta perspectiva como ponto de partida para a investigação, pensando articuladamente o que há de comum e de particular e analisando dialeticamente os processos de reestruturação urbana e das cidades.

\section{Os desafios de um estudo comparativo}

O fenômeno da globalização, cuja base está na emergência de uma unicidade técnica, unicidade do tempo e unicidade do motor da vida econômica e social, caracteriza-se pela adoção de uma racionalidade tida como única, cuja tendência é a homogeneização capitalista (Santos, 2008). Em contrapartida, cada território apresenta características próprias, resultado de suas formações socioespaciais, associadas em maior ou menor intensidade ao fenômeno da globalização e suas implicações.

Nos estudos sobre as cidades médias brasileiras, a relação entre espaços da semelhança e da diferença, isto é, derivados de lógicas constituídas globalmente e de resistências e readequações a estas lógicas, é bastante pertinente, tendo em vista que o advento do meio técnico-científico-informacional, favorecido pela modernização dos transportes e das comunicações, possibilitou a circulação do capital e a conquista de novas áreas geográficas, e favoreceu a emergência ou a consolidação de diversos centros urbanos não metropolitanos. 
Filipe Gomes Paulo

Assim sendo, os estudos comparativos mostram-se como uma abordagem interessante para compreender o processo de urbanização brasileira a partir das transformações nas cidades que representam importantes nós de intermediação nas redes urbanas do país.

Em suas contribuições sobre o método comparativo, Targa (1991: 266) indica três dimensões de análise que devem ser contempladas nos estudos: histórica, incorporando a dimensão temporal de longa duração; econômica e social, analisando as relações de produção na acumulação de capital e a evolução das relações de distribuição da propriedade e da renda, ou seja, abordando questões das relações de classe; e política, explorando as relações estabelecidas entre a sociedade civil e o Estado. Sua proposta de estudos comparados parte das diferenças entre as regiões do Brasil, entendendo que os contrastes podem "indicar as diferenças nas trajetórias históricas dessas regiões e as desigualdades a que chegaram” (Targa, 1991: 270).

Outro autor que também trabalha com a questão dos métodos comparativos é Brandão (2012). Ele assegura que o emprego deste método tem um papel fundamental nos estudos geográficos e em sua exposição indica três aspectos principais a serem considerados: um tratamento conceitual relativo à abordagem metodológica; uma revisão historiográfica do método no pensamento geográfico; e por fim, a pertinência da abordagem comparativa na geografia. Com base nestes três pontos, ele conclui que

[...] os estudos geográficos comparados servem, sobremodo, à tentativa de elucidar aspectos relativos à dialética das experiências induzidas ou diretamente capitaneadas por esses agentes hegemônicos em suas tentativas de promover a homogeneização dentro das heterogeneidades espaciais, bem como à análise dos posicionamentos opostos, resultantes, por sua vez, da ação de agentes locais (Brandão, 2012: 181).

Sob esta perspectiva, faremos algumas ponderações sobre o processo de reestruturação das cidades médias, obviamente sem dissociá-lo do processo de reestruturação urbana brasileira nas últimas décadas. Destacamos que determinadas comparações foram pensadas a partir do estudo realizado em Mossoró3, através do qual foi possível identificar características similares em outras cidades. As considerações serão apresentadas a partir de correlações entre os processos apontados por Sposito (2001) como motrizes da difusão do consumo nas cidades médias, definindo suas qualidades gerais, particulares e singulares, mediante as diferentes articulações que ocorrem em cada uma delas.

Objetivando uma exposição didática destes processos e dinâmicas a partir do consumo, traremos alguns exemplos representativos das cidades médias de Campina Grande (PB), Dourados (MS), Londrina (PR), Marabá (PA), Marília (SP), Mossoró (RN), Passo Fundo (RS), 
Filipe Gomes Paulo

e Uberlândia (MG)4, de formações socioespaciais específicas e relações políticas distintas, localizadas em diferentes regiões do país, conforme mostra o mapa 1.

Mapa 1 - Brasil. Cidades estudadas.

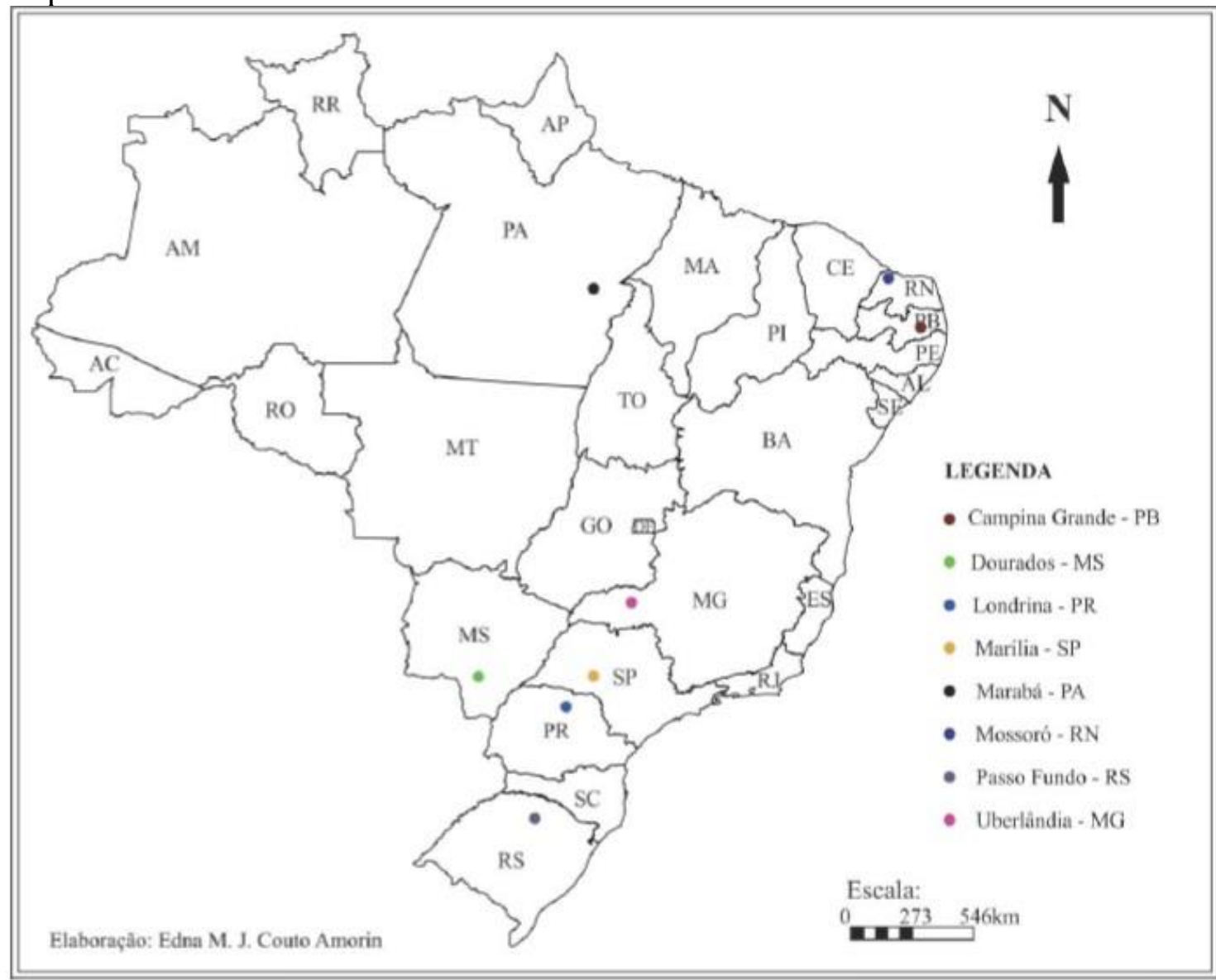

Fonte de Dados : IBGE- Censo Demográfico 2010

Iniciaremos nossa reflexão com "a tendência recente de concentração econômica das empresas industriais, associada aos meios técnico-informacionais atuais, que possibilitam comunicação imediata, viabiliza[ndo] a dissociação territorial entre o lugar das decisões e o da produção industrial" (Sposito, 2001: 630). No Brasil, este fenômeno teve início no final da década de 1960 e acelerou-se nas décadas seguintes, ocorrendo de maneiras distintas e em momentos diferentes em cada região do país.

Tomemos como exemplo a cidade de Marília, localizada no Estado de São Paulo, a 400 km da capital e com uma população de aproximadamente 216 mil habitantes de acordo com o último Censo Demográfico do Instituto Brasileiro de Geografia e Estatística (IBGE, 2010). A cidade teve seus papéis redefinidos a partir da desconcentração da indústria de transformação no Estado. Este processo compõe o quadro de uma nova divisão territorial do trabalho, no qual 
Filipe Gomes Paulo

a metrópole paulista centraliza as atividades de gestão e as demais regiões assimilam funções da produção industrial. Após um longo processo de transformações no setor, houve uma especialização produtiva na cidade de Marília, levando-a a ser reconhecida como a capital nacional do alimento (Melazzo, 2012). Outro setor industrial importante é o de metal-mecânica, com grande diversidade de produtos e potencial de incorporação tecnológica. Tais qualidades ampliaram as ofertas de emprego, sobretudo os de maior qualificação, com melhor formação intelectual e profissional, e, por conseguinte, alargaram a capacidade de consumo do mercado local e regional.

Em outras regiões do país, como o Norte e o Nordeste, o processo de desconcentração industrial ocorreu somente a partir dos anos 1980. Um caso interessante é o de Marabá, situada no sudeste paraense, com uma população de pouco mais de 230 mil habitantes (IBGE, 2010). Marcada por diversos ciclos econômicos - como o da borracha, da castanha e da extração de ouro -, a cidade passou por um processo de reestruturação urbana e da cidade a partir dos anos de 1970, principalmente perante a inserção em uma nova divisão interregional do trabalho, por exemplo, com a chegada da Companhia Vale do Rio Doce e a estruturação de redes rodoviárias, dinamizando sua economia e intensificando os fluxos. Assim, através da Companhia de Desenvolvimento Industrial do Pará (CDI) instalou-se o Distrito Industrial de Marabá (DIM), como base de um polo siderúrgico visando o minério de ferro de Carajás, explorado pela Vale S.A., em fins da década de 1980. Desde os anos 2000 houve uma diversificação e expansão do parque industrial da cidade, embora ainda concentre grande quantidade de indústrias no setor siderúrgico e da agroindústria (Rodrigues, 2010).

Uma segunda dinâmica importante no processo de disseminação do consumo nas cidades médias é "o declínio progressivo dos custos e a melhoria e diversificação dos sistemas de transportes e de telecomunicações [...] e a decorrente diminuição da participação relativa desse custo no preço das mercadorias" (Sposito, 2001: 631). Além de tornar viável a deslocalização industrial, a modernização dos transportes e das comunicações estimulou os deslocamentos de vários segmentos sociais para o consumo de bens e serviços especializados. A ampliação da oferta desses bens e serviços motiva a concentração em torno de espaços de maior densidade e dos mais sofisticados equipamentos comerciais e de serviços, os quais podem ser encontrados em cidades médias. Neste contexto, elas atraem consumidores de outras cidades e tornam-se centros polarizadores regionais, com raio de alcance de acordo com as infraestruturas disponíveis que articulam as cidades aos sistemas de circulação. 
Filipe Gomes Paulo

Por intermédio do consumo, intensificam-se, além dos fluxos estabelecidos nas escalas intraurbana e regional, os fluxos entre cidade e espaços rurais, e no caso específico de Dourados, que devido à sua localização geográfica ao sul do estado do Mato Grosso do Sul, próxima à fronteira com o Paraguai, mantém interações espaciais com cidades deste país, como Pedro Juan Caballero. Com pouco mais de 196 mil habitantes (IBGE, 2010), Dourados tem uma área de influência superior a $250 \mathrm{~km}$, destacando-se regionalmente como centro comercial e, sobretudo, de serviços associados à agricultura, à saúde (atendimento médico-hospitalar) e à educação (ensino superior), denotando uma particularidade da cidade (Silva, 2011).

Em outro contexto histórico e socioespacial, Campina Grande também se constitui historicamente como um importante centro de atividades comerciais e de serviços - desde as feiras de gado -, e mais recentemente, a partir dos anos 1980, como polo tecnológico. Distante 132 km da capital do estado da Paraíba, João Pessoa, a cidade de Campina Grande apresenta o crescimento do consumo de bens "modernos" e uma notável informatização bancária e de serviços especializados, reforçando uma ideologia de propagação da modernização marcada pela desigualdade e pela exclusão (Cardoso; Maia, 2007).

A terceira dinâmica apontada por Sposito (2001: 632) como motriz do consumo nas cidades médias são “as formas contemporâneas de organização espacial das atividades econômicas ligadas ao comércio de bens e serviços", que nas últimas décadas têm ampliado as escalas de abrangência do mercado regional através da modernização dos transportes e das comunicações, permitindo a estruturação de redes de múltiplas filiais, de supermercados e hipermercados e de shopping centers, a partir do intenso processo de concentração econômica do comércio no Brasil.

Com isso, houve a deslocalização e desconcentração destes equipamentos para outras cidades que não as metrópoles, processo estimulado pela entrada de capitais estrangeiros e pela adoção de estratégias de fusão e concentração econômica, acirrando a competitividade entre empresas e exigindo investimentos maiores em marketing. Como destacam Salgueiro e Cachinho (2009: 20-21), "mais do que bens e serviços, [...] um grande número de estabelecimentos está empenhado em oferecer aos consumidores verdadeiras experiências de vida". Isto muda a forma e o conteúdo destas atividades, estimulando novos padrões de consumo de massa, alterando hábitos e costumes locais e, sobretudo, redefinindo as centralidades urbanas e desencadeando novas relações socioespaciais.

Obedecendo a estratégias de localização, acessibilidade e viabilidade econômica, o shopping center, assim como as redes de supermercados e hipermercados, são hoje 
Filipe Gomes Paulo

significativos exemplos destas novas formas comerciais. Desde fins da década de 1980, e sobremaneira, nos anos 2000, acelerou-se a dispersão territorial destes equipamentos modernos para as cidades médias, cujas localizações geográficas privilegiadas propiciam a polarização de mercados consumidores. Esta mudança na organização espacial das atividades comerciais e de serviços atende a lógicas econômicas globais, podendo ser observada claramente nas cidades médias brasileiras. Assim como as demais cidades mencionadas, Londrina (PR) e Uberlândia (MG) também respondem a este processo de dispersão espacial com o crescimento do número de estabelecimentos deste tipo.

Em Londrina, cidade do norte paranaense com população estimada em pouco mais de 500 mil habitantes (IBGE, 2010), a entrada de grandes capitais estrangeiros no setor supermercadista, por exemplo, ocorreu no início dos anos 1990, com a instalação de um grande grupo internacional em uma das vias de acesso à cidade, ao lado de um shopping center (Silva, 2009). No tocante a este segmento (shopping center), atualmente existem dois empreendimentos representativos em funcionamento na cidade e outros três em construção, com a participação de capitais de grupos locais, nacionais e até internacionais, que possuem, inclusive, investimentos semelhantes em outras cidades.

Assim como Londrina, a cidade de Uberlândia, localizada no Triângulo Mineiro, no Estado de Minas Gerais, também apresenta novas dinâmicas nas atividades comerciais e de serviços, particularmente por sua excelente posição e situação geográfica. Ainda na década de 1970, a cidade passou por expressiva refuncionalização urbana e hoje tem uma população superior a 600 mil habitantes (IBGE, 2010), com importante participação no setor industrial, particularmente associado à agroindústria. Entretanto, é o setor de serviços e o comércio atacadista e de distribuição de mercadorias que têm maior destaque na economia da cidade, dando-lhe o título de "capital do atacado", e esta qualidade foi favorecida pelo desenvolvimento da infraestrutura de transportes e de comunicações (Soares et al., 2010).

Por fim, o quarto processo assinalado "é no campo do consumo de bens e serviços especializados ligados à modernização do setor agropecuário, que se tem visto um avanço significativo do papel comercial e de serviços das cidades de porte médio" (Sposito, 2001: 634). Com relação a este aspecto, há a sobreposição de dois tipos de consumo: um de escala local e microrregional, onde se verifica maior proximidade entre comprador e vendedor; e outro de escala mesorregional e nacional, cujos fluxos resultam das interações espaciais. Ressalta-se também a integração das atividades agrícolas associadas à agroindústria ao circuito da economia urbana, ampliando a produção material e imaterial, e, por conseguinte, 
Filipe Gomes Paulo

revolucionando o consumo (Elias, 2003). Assim, partindo do crescimento do consumo produtivo e consuntivo a partir do desenvolvimento de atividades associadas à agropecuária e ao agronegócio, podemos pensar diferentes realidades regionais no país, como as das cidades de Mossoró (RN) e Passo Fundo (RS).

Localizada entre duas capitais nordestinas, a $277 \mathrm{~km}$ de Natal (RN) e a $260 \mathrm{~km}$ de Fortaleza (CE), Mossoró é o segundo município mais populoso do Estado do Rio Grande do Norte, com 259.886 habitantes, dos quais 91\% vivem na área urbana (IBGE, 2010). Com uma economia bastante heterogênea, baseada nas atividades terciárias e em três outras importantes atividades econômicas - agronegócio da fruticultura tropical (especialmente melão e banana), exploração do petróleo e do gás natural e da extração e beneficiamento do sal -, a cidade assumiu a partir da década de 1980 novos papéis na divisão internacional do trabalho. No contexto da quarta dinâmica apresentada por Sposito (2001), destacamos a incorporação do vale do Açu (região onde está Mossoró) aos circuitos produtivos globalizados no setor do agronegócio da fruticultura, que promoveu uma reorganização do espaço produtivo, uma dinamização da economia urbana (com o crescimento do consumo, produtivo e consuntivo) e uma reestruturação urbano-regional (Elias; Pequeno, 2010).

Com a particularidade de uma formação socioespacial diretamente relacionada às atividades agrícolas, Passo Fundo sempre exerceu papel articulador de apoio às atividades do campo na região do Planalto Médio, no norte do estado do Rio Grande do Sul. Ainda nos anos 1940 a cidade era importante produtora de trigo para abastecimento do mercado nacional, porém foi a partir dos anos 1970 que a cidade consolidou-se como polo de serviços para o agronegócio da soja, tanto como plataforma logística para a produção e distribuição de grãos (favorecida pela condição de entroncamento rodoviário e ferroviário), quanto centro de informação especializada e pesquisa aplicada, fortalecendo o desenvolvimento de atividades comerciais e de serviços (Sobarzo, 2010).

Deste modo, os elementos apresentados nos sugerem uma investigação comparativa no intuito de avançar nos debates sobre cidades médias, apontando características particulares e gerais entre elas, além de contribuírem para pensar o consumo e sua relevância nestas cidades. A exposição destes quatro processos impulsionadores do consumo em cidades médias brasileiras indica que a difusão do meio técnico-científico-informacional nas cidades possibilitou a urbanização do território, no qual há uma difusão mais ampla no espaço das variáveis e dos nexos modernos (Santos, 2005), promovendo a ampliação da sua estrutura urbana e regional, o crescimento das suas atividades econômicas, o aumento do consumo de bens e serviços 
Filipe Gomes Paulo

modernos, a instalação de novos fixos associados às formas modernas de distribuição de mercadorias e o estabelecimento de novos fluxos intra e interurbanos.

\section{Considerações finais}

Buscamos traçar elementos comuns a partir de processos ocorridos em diferentes escalas, considerando as diferentes realidades regionais e urbanas. Além dos processos supracitados associados ao crescimento do consumo nas cidades médias brasileiras, que tiveram rebatimentos diferentes em cada cidade e região, indicamos outras questões que permeiam a discussão sobre o consumo, dentre as quais mencionamos a difusão do crédito, o papel da propaganda e as novas sociabilidades decorrentes dos novos padrões de consumo.

Associado ao aumento da renda da população e do emprego, o crédito é apontado como um dos fatores fomentadores do fenômeno "consumista" no país5. Harvey $(2005,2007)$ afirma que a ampliação do sistema internacional de crédito é fator essencial para a criação de um mercado mundial e a formação da sua estrutura, sustentado pela concentração do poder das instituições financeiras e pelo surgimento de novos instrumentos e mercados financeiros capitalistas. Além disso, a disseminação do crédito amplia o acesso ao consumo e, no caso de muitas cidades médias, são condição e consequência de uma reestruturação econômica.

Um segundo aspecto interessante, sobretudo para as atividades comerciais modernas, é a crescente utilização da publicidade e do marketing pelas grandes empresas, importantes ferramentas de estímulo ao consumo, através da ampliação das demandas, necessárias ou não, da sociedade. Deste modo, a propaganda atua diretamente sobre os indivíduos como consumidores, manipulando-os comercial e culturalmente, desencadeando duas tendências poderosas no desenvolvimento do consumo: a mobilização da moda em mercados de massa e a passagem do consumo de bens para o consumo de serviços (Harvey, 2007).

Acerca das mudanças na sociabilidade local e regional de algumas cidades médias, sobretudo naquelas em que as transformações foram mais velozes e intensas, apontamos algumas bastante pertinentes, tais como: a expansão do horário possível de compras, principalmente com a chegada de shopping centers, supermercados e hipermercados; transformações na atividade comercial, com a aceleração do consumo de bens duráveis; e o incremento da alimentação fora de casa, associado às mudanças nos hábitos alimentares (fast food) (Elias; Pequeno, 2010). 
Filipe Gomes Paulo

Outro destaque importante é que tais processos evidenciam novas formas de produção e de consumo da cidade. O espaço, "um verdadeiro campo de forças cuja aceleração é desigual" (Santos, 2002: 153), tornou-se também mercadoria e como tal vem sendo apropriado e assim vendido pelas construtoras e incorporadoras, as quais assinalam as áreas de valorização nas cidades e, com isso, aprofundam as desigualdades socioespaciais no espaço urbano. Evidentemente, neste processo o Estado tem papel fundamental ao implantar infraestruturas urbanas, elaborar projetos e contribuir para a adaptação da cidade aos moldes exigidos pelas grandes empresas, baseadas na concentração financeira e espacial.

Portanto, pensar o processo de reestruturação urbana e reestruturação das cidades médias brasileiras relacionando-os à expansão do consumo não é uma tarefa fácil, sobretudo se realizarmos este feito a partir de uma análise comparativa entre cidades, no sentido de apreender suas distintas formações econômicas e socioespaciais, sem desconsiderar processos ocorridos em outras escalas geográficas, definindo assim, suas particularidades e generalidades

\section{Referências}

BRANDÃO, Carlos Antônio (2010); "Producción social del ambiente construído y sus escalas espaciales: notas para una teoria acerca de las acciones y decisiones de sujetos concretos". In: FERNANDEZ, V.R.; BRANDÃO, C (org.). Escalas y políticas del desarrollo regional. Buenos Aires: Miño y Dávila. p.241-273.

BRANDÃO, Paulo Baqueiro (2012); "Velhas aplicações e novas possibilidades para o emprego do método comparativo nos estudos geográficos". GeoTextos, v.8, n.1, jul.2012. p.167-185. DOI: http://dx.doi.org/10.9771/1984-5537geo.v8i1.5555

CARDOSO, Carlos Augusto de Amorim; MAIA, Doralice Sátyro (2007); "Das feiras às festas: as cidades médias do interior do Nordeste". In: SPOSITO, Maria Encarnação Beltrão (org.). Cidades médias: espaços em transição. São Paulo: Expressão Popular. p. 517-550.

ELIAS, Denise (2003); Globalização e agricultura: a região de Ribeirão Preto - SP. São Paulo: EDUSP.

ELIAS, Denise; PEQUENO, Renato (2010); "Mossoró: o novo espaço da produção globalizada e aprofundamento das desigualdades socioespaciais". In: SPOSITO, Maria Encarnação Beltrão; ELIAS, Denise; SOARES, Beatriz Ribeiro. (orgs.). Agentes econômicos e reestruturação urbana e regional: Passo Fundo e Mossoró. São Paulo: Expressão Popular. p. $101-283$

HARVEY, David (2007); Condição pós-moderna: uma pesquisa sobre as origens da mudança cultural. 16. ed. São Paulo: Loyola. 
Filipe Gomes Paulo

(2005); A produção capitalista do espaço. São Paulo: Annablume.

INSTITUTO BRASILEIRO DE GEORGRAFIA E ESTATÍSTICA - IBGE (2010); Censo Demográfico.

MELAZZO, Everaldo Santos (2012); "Marília: especialização industrial e diversificação do consumo. Trajetórias de uma cidade média". In: SPOSITO, Maria Encarnação Beltrão; ELIAS, Denise; SOARES, Beatriz Ribeiro. (orgs.). Agentes econômicos e reestruturação urbana e regional: Chillán e Marília. São Paulo: Expressão Popular. p.161-279.

ORTIGOZA, Silvia Aparecida Guarnieri (2008); "Velhas e novas espacialidades do comércio e do consumo nas cidades". In: ENCONTRO NACIONAL DE GEÓGRAFOS, 15., 2008, São Paulo. Anais... São Paulo. 12 p.

PADILHA, Valquíria (2006); Shopping center: a catedral das mercadorias. São Paulo: Boitempo.

RODRIGUES, Jovenildo Cardoso (2010); Marabá: centralidade urbana de uma cidade média paraense. 188f. Dissertação (Mestrado) - Universidade Federal do Pará, Núcleo de Altos Estudos Amazônicos, Programa de Pós-Graduação em Desenvolvimento Sustentável do Trópico Úmido, Belém.

SALGUEIRO, Teresa Barata; CACHINHO, Herculano (2009); "As relações cidadecomércio. Dinâmicas de evolução e modelos interpretativos". In: CARRERAS, Carles; PACHECO, Susana Mara Miranda (Orgs.). Cidade e comércio: a rua comercial na perspectiva internacional. Rio de Janeiro: Armazém das Letras. p. 9-39.

SANTOS, Milton (2008); A natureza do espaço: técnica e tempo, razão e emoção. 4. ed. São Paulo: EDUSP.

(2007); Pensando o espaço do homem. 5. ed. São Paulo: EDUSP.

(2005); A urbanização brasileira. 5. ed. São Paulo: EDUSP.

(2002); Por uma geografia nova: da crítica da geografia a uma geografia crítica. São Paulo: EDUSP.

(1998); O espaço do cidadão. 4. ed. São Paulo: Nobel.

(1996); Técnica, espaço, tempo: globalização e meio técnico-científico-informacional.

2. ed. São Paulo: Hucitec.

SILVA, Valéria Ferreira da (2011); Os papéis de Dourados - MS no contexto regional: apontamentos para análise de uma cidade média. 166 f. Dissertação (Mestrado em Geografia) - Universidade Federal da Grande Dourados. Dourados.

SILVA, William Ribeiro da (2009). "Dinâmica de reestruturação em Londrina. Agentes econômicos e suas escalas". In: XI Simpósio Nacional de Geografia Urbana, 2009, Brasília. XI Simpurb. Brasília: Universidade de Brasília, v. 1. p. 1-20. 
Filipe Gomes Paulo

SOARES, Beatriz Ribeiro et al. (2010); "Uberlândia (MG): leituras geográficas de uma cidade média em transição". In: ELIAS, Denise; SPOSITO, Maria Encarnação Beltrão; SOARES, Beatriz Ribeiro. (orgs.). Agentes econômicos e reestruturação urbana e regional: Tandil e Uberlândia. São Paulo: Expressão Popular. p.159-285.

SOBARZO, Oscar (2010); "Passo Fundo: cidade média com funções comerciais, de serviços e de apoio ao agronegócio". In: SPOSITO, Maria Encarnação Beltrão; ELIAS, Denise; SOARES, Beatriz Ribeiro. (orgs.). Agentes econômicos e reestruturação urbana e regional: Passo Fundo e Mossoró. São Paulo: Expressão Popular. p. 31-105.

SPOSITO, Maria Encarnação Beltrão (2010); "Desafios para o estudo das cidades médias". In: XI Seminário Internacional de la Red Iberoamericana de Investigadores sobre Globalización y Territorio, 2010, Mendoza. Trabalhos completos. Mendoza: UNCUYO - Universidad de Cuyo. p. 1-18.

(2009); “Globalização, consumo e papéis intermediários de cidades médias no Brasil". In: Carmen Bellet Sanfeliu; Maria Encarnação Beltrão Sposito. (Org.). Las ciudades medias o intermedias en un mundo globalizado. Las ciudades medias o intermedias en un mundo globalizado. 1a.ed.Lleída: Edicions de la Universitat de Lleída. p. 41-69.

(2007); "Cidades médias: reestruturação das cidades e reestruturação urbana". In: SPOSITO, Maria Encarnação Beltrão (Org.). Cidades médias: espaços em transição. São Paulo: Expressão Popular. p.233-253.

(2006); "O desafio metodológico da abordagem interescalar no estudo das cidades médias no mundo contemporâneo". Cidades, v. 3, n. 5. p. 143-157.

(2001); "As cidades médias e os contextos econômicos contemporâneos". In: . (Org.). Urbanização e cidades: perspectivas geográficas. Presidente Prudente: GasPERR. p. 609-643.

SPOSITO, Maria Encarnação Beltrão et al (2007); “O estudo das cidades médias brasileiras: uma proposta metodológica". In: Paulo: Expressão Popular, p. 35-67. . (Org.). Cidades médias: espaços em transição. São

TARGA, Luiz Roberto Pecoits (1991); “Comentário sobre a utilização do método comparativo em análise regional”. Ensaios FEE, Porto Alegre, 12 (1): 265-271. 